\title{
Geophysical surveys of rock mass status of iron ore deposit with combined deep - opencast mining zone
}

\author{
Andrey Vedernikov ${ }^{1 *}$, Pavel Zuev ${ }^{1}$, and Danila Grigoriev ${ }^{1}$ \\ ${ }^{1}$ The Institute of Mining of the Ural branch of the Russian Academy of Sciences, 620075, \\ Ekaterinburg, Russia.
}

\begin{abstract}
Often in deposits developed by underground mining, the task is to control the state of the earth's surface within the mine field. And this problem is even more acute in the case of combined open-underground mining. The Goroblagodatskoe iron ore deposit has been developed by a combined method for more than 40 years. The article describes the methodology and results of applying the geophysical diagnostic method at a mining facility developed by a combined open-underground method - the spectral seismic profiling method (SSP). The application of this method is justified. This method has shown its sufficient efficiency in terms of time costs and sufficient reliability for local studies. The results of field and desk studies are obtained, an assessment of the nature of the object is given, which justifies the use of further measures for the safe development of the object.
\end{abstract}

\section{Introduction}

A special place in the geophysical surveys is occupied by diagnostics of the state of rock massifs of sub-developed territories, for the purpose of further exploitation of their ground surface. Practice shows that the methods used for diagnostics, in most cases, give a reliable picture of the state of the rock massif, which is confirmed by various other geophysical, geological and geodetic survey methods $[1,2]$.

No less important objects of research are rock masses, simultaneously developed by underground and open-pit methods. In this case, surveys were completed at an object of this type, developed by a combined open-underground method - the Goroblagodatskiy iron ore deposit.

\section{Site Geology}

The Goroblagodatsky magnetite deposit, discovered in 1728, is located in an intensely deployed volcanic-sedimentary complex of Lower Silurian rocks. Basalts and their tuffs, tuffconglomerates, tuff-gravelites, tuff-sandstones and, according to them, ore bodies of a stratiform shape plunge eastward, forming a monocline. In the southern part of the field, the

\footnotetext{
${ }^{*}$ Corresponding author: avedernikov@igduran.ru
} 
monocline is limited by the steeply falling contact of the Kushvinsky diorite-syenite intrusion. The formation of the plutonic complex was accompanied by the breakthrough of the ore-bearing layer by subvolcanic formations (dikes) of microsienites and syenite porphyry, which are widely distributed in the field. These are two varieties of vein rocks connected by gradual transitions, forming single bodies. Microsyenites - a fine-grained, tabular-granular structure with a uniform texture. Syenite-porphyry with plagioclase inclusions and dense fine-grained bulk.

When dikes were introduced into magnetite ores, in some cases, there was a partial dissolution of previously formed minerals, instead of which formed potassium feldspar, pyroxene, scapolite, magnetite recrystallized, resulting in the formation of "smallpox" or pyroxene-magnetite ores. As the distance from the dyke, the degree of transformation decreased to their complete disappearance, where the ores retained their textural and structural primary features. On the other hand, the movement of the magmatic melt led to plastic deformations and partial remelting of minerals in areas adjacent to the dykes with the formation of magnetite rims. The rim of magnetite ores was formed by pulling magnetite to the outer edge of the dikes. In the dike itself, magnetite grains acquired elongated shapes, the orientation of which coincides with the contact position.

Magnetite is a mineral with a rather complex and diverse chemical composition. Different generations of the magnetite mineral arising at different stages of deposit formation and at different distances from the intrusion differ in composition, shape, size and physical properties. When an intrusion is introduced in the contact zone, the iron content increases, magnetite grains are enlarged and it is cleared of impurity elements.

\section{Problem Set}

The firstly question about the safety of this type of development was raised in 1976, when it was decided to open-pit develop reserves of a safety barrier that separated the Central quarry from the zone of Yuzhnaya mine underground operations influence. As a result, there was a direct intersection of open and underground mining zones. The south side of the quarry was spread directly into the mine collapse zone. The successful mining of the safety barrier reserves was ensured by scientific projects [3], in accordance with the regulations of the current regulatory documents [4,5], and monitoring the displacement processes.

Since it is highly probable that an object of this type of mining can form craters, sinkholes and collapses in the open-type mining zone in the presence of man-made voids directly under the quarry, it was decided to use spectral seismic prospecting (SSP) to study the rock mass, which allows us to assess the presence of non-uniformity and cavities at a depth up to $250 \mathrm{~m}$ $[6,7]$. The choice of this method of geophysical surveys is justified by its good resolution for solving such tasks and wide experience in conducting appropriate research on ore deposits with an open-cast method of mining. The method is well established for evaluating the structural state and geomechanical state of rock mass in ore deposits.

The idea of the method is to use the dependencies between the spectral composition of its sensor's own oscillatory process that occurs when it hits a rock surface, and the structure of the probed rock mass. Structural non-uniformity of the massif detected by this method are surfaces where there is no adhesion between rocks - i.e., sliding surfaces. Adjacent structural blocks slip through these contacts when their own elastic vibrations are excited in them, as a result of which mobile structures can be detected even when they are separated by closed cracks. For measurements, small-scale equipment of "NTF Geofizprognoz" is used. Elastic vibrations of the rock mass are manually excited by applying a short hit to the rock outcrop in the immediate vicinity of the seismometer [7]. During the survey implementation, profile lines are laid in the area of the object under study, their number, location and the number of shooting points on the profile line is selected based on various conditions. 
Currently, the Central pit of deposit Goroblagodatskoe reached a depth at $+60 \mathrm{~m}$ and has parameters: $1450 \times 1100$ meters at top; $520 \times 40$ meters at bottom. The maximum pit depth is about 200 meters. At the time of termination of mining operations, the Western, Northern and Eastern sides of the quarry were partially extinguished to the horizon of $+80 \mathrm{~m}+162 \mathrm{~m}$. The southern side of the quarry in the section of the funnel formation zone from underground mining operations of the Yuzhnaya mine is in an intermediate position.

Mining and geological conditions of the Goroblagodatskoye deposit are quite favorable for opencast mining. Iron ores and host rocks in the whole deposit are quite stable and only in zones of tectonic disturbances the stability of rocks decreases, which affects the values of the angles of slopes of ledges and sides of the quarry.

Tectonic faults are confined to two directions - submeridional and sublatitudinal. Tectonic faults in these two directions are characterized by well-defined displacement planes with friction clay gouge and are accompanied by zones of crushing, the thickness of which reaches several meters. A characteristic feature of faults is their well-defined planar nature and steep, almost vertical fall. All of them have a rather complex structure.

\section{Methodology}

Surveys at Central quarry field to study the degree of rock masses undermining carried out on the ledges of the overlap area of underground and open-cast mining and in adjacent areas within the zone of collapse of past and modern, emerging from the ongoing underground development. In total, 9 profile lines with a total length of about 2,600 m were passed on the territory under study (Fig.1).

The length of the profile lines, depending on the terrain, ranged from 90 to 730 meters. The shooting step on the profile lines was equal to 5 meters, which eliminates the possibility to skip cavities that can cause the sudden formation of sinkholes and craters of collapse. All work was carried out in compliance with safety measures with a preliminary assessment of the state of the ledges.

In accordance with the purpose of the surveys, the sounding depth is 250 meters, which allows reaching the lying side in the western part of the overlap zone, and in the eastern part, where modern mining operations at the mine are carried out at $-160 \mathrm{~m}$ and $-240 \mathrm{~m}$ horizons (depth from surface $420-500 \mathrm{~m}$ ), cover with a sounding for thickness sufficient to ensure the safety of open work.

Further, as a result of the interpretation, spectral seismic sections were constructed for all profile lines, reflecting the degree of disintegration of the rock mass as a result of displacement from underground mining. For a reasonable assessment of the possibility of implementing open pit mining in the zone of overlapping the open pit with underground mining, the spectral seismic sounding profiles were positioned in such a way as to cover all the temporary stages of the formation of the collapse zone from the development of the upper horizons of $+120 \mathrm{~m}$, $+60 \mathrm{~m}$ to modern working horizons of $-160 \mathrm{~m}$ and $-240 \mathrm{~m}$. This made it possible to assess the state of the mined rock mass with different periods of existence of the collapse zone from several decades to modern operating and developing sites.

The studies using spectral seismic profiling revealed zones of distribution of three specific states of the rock mass: zones of disintegrated rocks formed in tectonic faults; zones of disintegrated rocks that arose under the influence of the displacement process; zones of primary rocks that have preserved to some extent the original structure of the rock mass (Fig.2). Zones of disintegrated rocks associated with tectonic faults are manifested when the profile line passes directly along the tectonic fault, coinciding with it in the direction. 


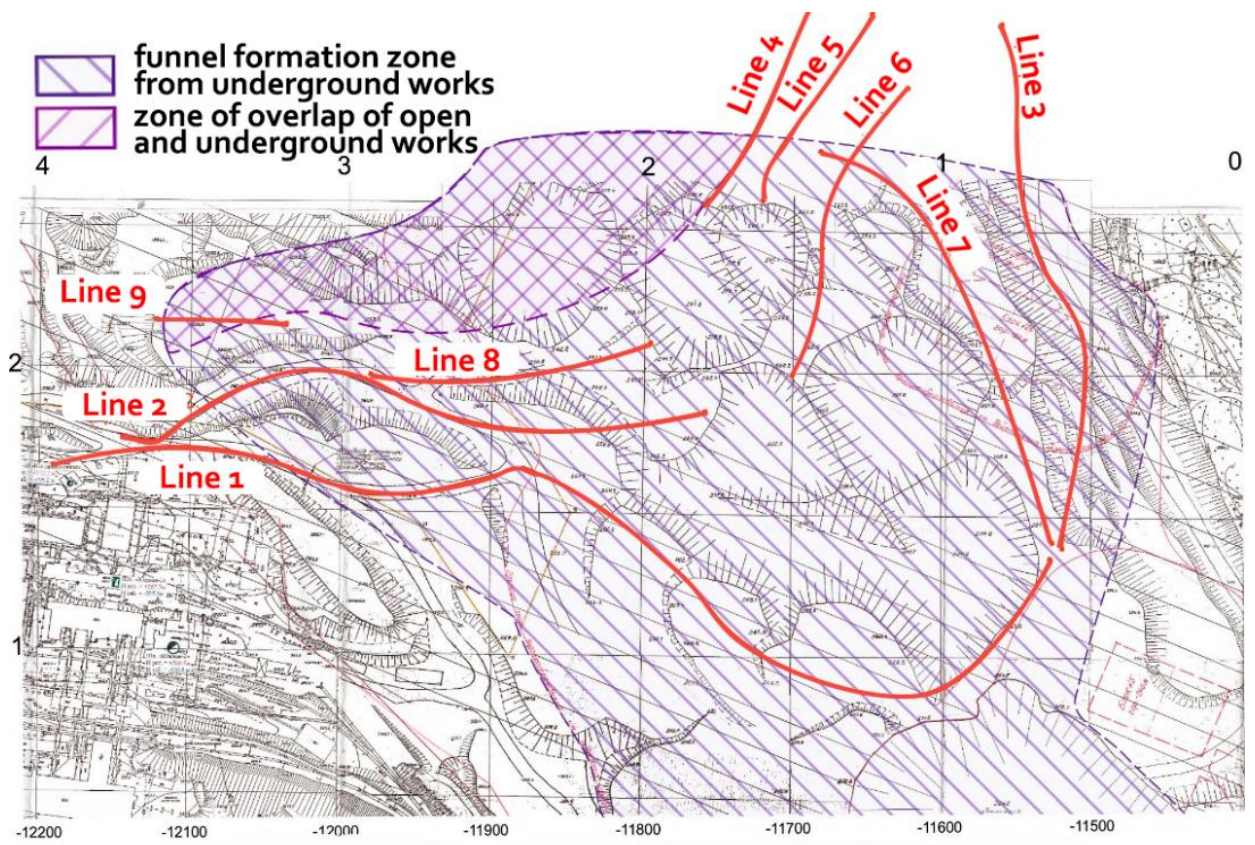

Fig.1. Geophysical profiles of spectral seismic prospecting.

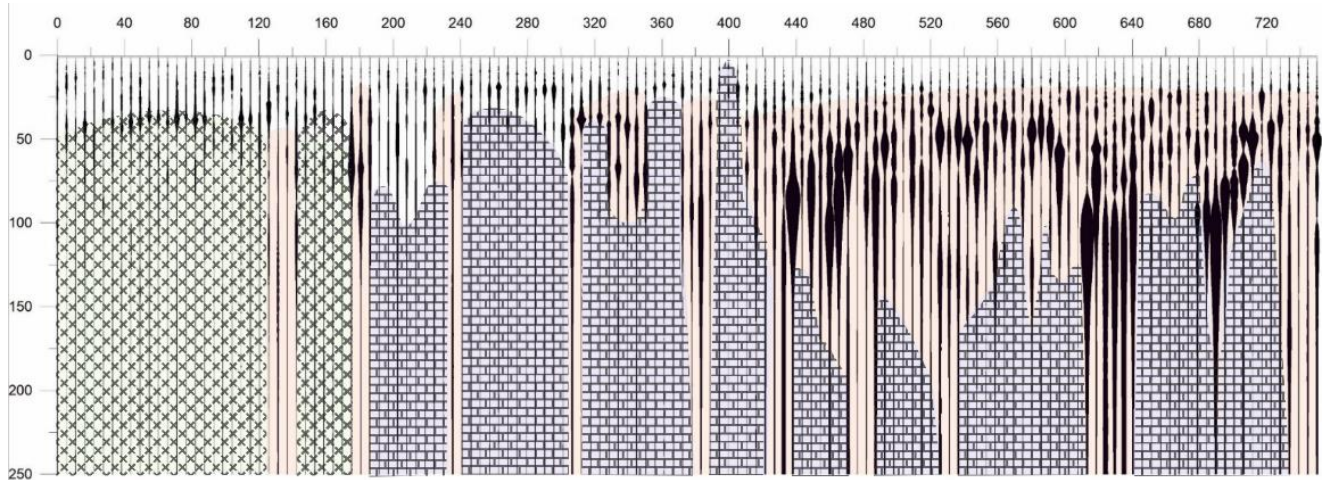

$x_{x \times x}^{x} \quad$ - zones of weakened rocks formed in tectonic disturbances

- zones of primary rocks

- zones of weakened rocks formed under displacement processes

Fig.2. Spectral seismic section along the Line 1.

Of the three stages of structural and material transformation of the mined rock mass, the final stage remains - the attenuation of deformations and subsidence due to compaction and consolidation of disintegrated rocks [1,9]. The behavior of the rock mass at this stage in the process of conducting open-pit mining depends on the completeness of the displacement process development at the previous stages.

Its full cycle includes the collapse of the underlying masses in the developed space and the subsequent compaction of the collapsed rocks, which depends on the parameters of the 
specific developed space and the overall degree of disintegrity of the site. If the isolated areas are small in size, the compaction process may be delayed and the developed space will be filled with loosened rocks. When opening such areas, the development of local molds of displacement is possible.

\section{Results and conclusions}

As a result of geophysical surveys, the following conclusions were made:

- the overlapping section of underground and opencast mining is located in the collapse zone from underground mining of previous years, where the active stage of the collapse process has already completed and the collapsed rocks are being compacted;

- in the rock mass of the collapse zone of previous years, there are no voids that can cause sudden formation of sinkholes and craters of collapse.

Thus, geophysical surveys of the rock mass state in the caving zone revealed two important circumstances in predicting the displacement process development and for taking measures to ensure the safety of open cast mining. Firstly, in the mosaic pattern of alternating zones with varying degrees of rock disintegration, the parameters of open-pit mining should be taken based on the conditions that the massif has substantially lost its strength and deformation characteristics due to the effect of the displacement process.

Secondly, in the overall picture of the deformation processes, there will be local displacement molds in which subsidence processes will occur more intensively and can reach the criteria of the collapse zone, i.e. more than $250 \mathrm{~mm}$.

Article completed for State Task 0405-2019-0007.

\section{References}

1. S.V. Usanov, Geomechanical assessment of the possibility of using the developed areas. Abstract of Cand. diss., 21 (Yekaterinburg IGD UrB RAS, 2011)

2. T. Sh. Dalatkazin, Yu. P. Konovalova, V. I. Ruchkin, P. I Zuev, Izvestiya Tula State University. Sciences of Earth, 4, 206 (2018)

3. A.D. Sashurin, Research on the safe conduct of open pit mining by the Central quarry of GBRU in the collapse zone of the Yuzhnaya mine, Report on research of the IGD UB RAS. Hand, 39 (Ekaterinburg, 1976)

4. Rules for the protection of structures and natural objects from the harmful effects of underground mining in the iron ore deposits of the Urals and Kazakhstan. Approved USSR Ministry of Defense 02.08.1990. Acc. Gospromat supervision of the USSR 06/21/1990, 64 (Sverdlovsk, 1990)

5. Instructions on the procedure for approving measures to protect buildings, structures and natural objects from the harmful effects of mining. RD-07-54-94. Approved Gosgortekhnadzor of Russia, (March 28, 1996)

6. A. D. Sashurin, The study of the state and the level of underworking of the rock mass on the southern side of the central quarry in the funnel formation zone from underground work South and preparation of a conclusion on the possibility of conducting open-cast mining in the part-time zone. Report on research of the IGD UB RAS. Hand, 45 (Ekaterinburg, 2011)

7. A. G. Glikman, Physics and practice of spectral seismic exploration, URL: http://www.newgeophys.spb.ru/.

8. A. A. Panzhin, T.F. Kharisov, O. D. Kharisova, Journal of Mining Science 4, 10 (2019)

9. V. V. Melnik, A.L. Zamyatin, Problemy nedropolzovaniya, 3, 60 (2017) 